\title{
PENGARUH INTENSITAS CAHAYA TERHADAP DEGRADASI WARNAAGAR- AGAR YANG DIWARNAI SARI UMBI BIT MERAH (Beta vulgaris L. var. rubra L.)
}

\section{THE EFFECT OF LIGHT INTENSITY ON THE COLOR DEGRADATION OF JELLY COLORED BY RED BEET (Beta vulgaris L. var. rubra L.) JUICE}

\author{
Lydia Ninan Lestarioo $^{1)}$, Noviana Gunawan"1), Yohanes Martono ${ }^{1)}$
}

Diterima 4 Juni 2012, disetujui 12 November 2013

\begin{abstract}
The aims of this research were to determine the concentration of beetroot juice in jelly which panelists like best; to determine the color degradation rate constant in jelly colored with beetroot juice caused by sunlight and fluorescent light; and color degradation rate constant of jelly colored with synthetic colorant.

The organoleptic test used 2,5 percent; 5 percent; 7,5 percent; 10 percent; and 12,5 percent beetroot juice and permitted synthetic colorant for food. The light intensity to test the beetroot color stability in jelly were 879,06 lux, 1.688,54 lux, 2.342,2 lux and 6.752,2 lux.

The results showed that the concentration of beetroot juice which panelists like best was 5 percent.; The color degradation rate constant of jelly colored by 5 percent beetroot juice on intensity 879,06 lux was 0,0468 hour $^{-1}$; 1.688,54 lux was 0,0565 hour-1; 2.342,2 lux was 0,0653 hour-1; $6.752,2$ lux was 0,0887 hour $^{-1}$. The higher the light intensity, the higher the degradation constant rate.
\end{abstract}

Keywords: beetroot, light intensity, color degradation rate

\section{PENDAHULUAN}

Warna merupakan faktor penting yang menentukan kualitas makanan. Bersama dengan aroma, rasa dan tekstur, warna memegang peranan penting dalam penerimaan makanan oleh konsumen. Beberapa waktu yang lalu, banyak digunakan pewarna sintetik untuk makanan karena mudah diaplikasikan, harganya relatif murah dan dapat disimpan lama. Namun, akhir-akhir ini banyak laporan yang menyatakan bahwa pewarna sintetik cenderung bersifat toksik dan karsinogen, terutama pewarna sintetik merah, seperti Red no. 3 dan Red no. 5 (Rodriguez, dkk, 1995). Oleh sebab itu perlu dicari pewarna merah alami yang aman sebagai pengganti. Salah satu bahan yang dapat dijadikan sebagai pewarna merah alami yang belum banyak digunakan adalah betalain. Pigmen merah keunguan ini dijumpai pada beberapa jenis tanaman seperti buah naga dan umbi bit merah. (Beta vulgaris L var. rubra L). Pigmen utama yang ada di dalam umbi bit merah adalah betasianin (mengandung 75\%-95\% betanin), sedangkan betaxantin berada dalam jumlah yang lebih sedikit. Betaxantin yang dominan di dalam bit merah yaitu Vulgaxantin I, sekitar 95 persen (Stintzing dkk., 2008).

Program Studi Kimia, Fakultas Sains dan Matematika, Universitas Kristen Satya Wacana J1 Diponegoro 52-60 Salatiga email:nlestario@gmail.com 

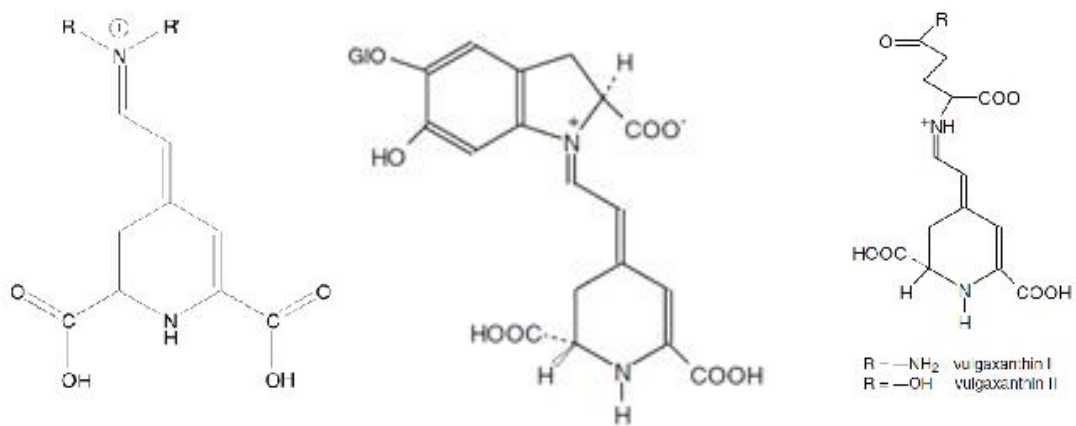

Gambar 1. Struktur betalain, betanin dan vulgaxanthin I dan II (Jeszka, 2007)

Pigmen betalain dari umbi bit ini aman digunakan sebagai pewarna makanan (Vargas dan Lopez, 2003). Hal yang sering menjadi masalah dalam penggunaan pewarna alami adalah stabilitasnya. Banyak hal yang mempengaruhi stabilitas warna selama penyimpanan, salah satunya adalah cahaya. Melihat kenyataan bahwa banyak produk pangan yang terpapar cahaya selama penjualan, terutama cahaya lampu, oleh sebab itu dalam penelitian ini diuji stabilitasnya terhadap cahaya.

Pada kondisi dengan disinari lampu fluorescent, kinetika degradasi betalain mengikuti pola reaksi orde-1 (Vargas dan Lopez, 2003). Betalain secara umum terdegradasi menjadi asam betalamat yang berwarna kuning dan cyloDOPA glukosida yang tidak berwarna (Jeszka, 2007).
Banyak makanan jajanan yang disukai anak diwarnai merah, seperti es krim, sirup, kue bolu, dan agar-agar. Umbi bit merah dalam penelitian ini diaplikasikan ke agar-agar, sebagai makanan yang disukai anak-anak, dan sering diwarnai merah, serta biasanya habis dalam sehari. Pemberian pewarna alami dari bit ini akan memberikan warna merah keunguan pada agaragar yang disebabkan oleh pigmen betalain. Warna merah keunguan ini lebih menarik minat konsumen dan merupakan inovasi terbaru yang diterapkan dalam pembuatan agar-agar.

\section{METODOLOGI PENELITIAN}

\section{Bahan dan Alat}

Bahan yang digunakan dalam penelitian ini antara lain: umbi bit merah (Beta vulgaris L.) yang diperoleh dari desa Kopeng, kab. Semarang. Bahan-bahan lain meliputi: agar-agar (Swallow,<smiles></smiles>

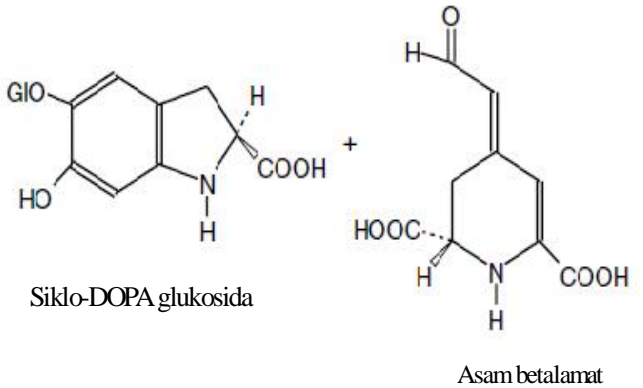

Gambar 2. Degradasi betanin secara umum (Jeszka, 2007) 
putih), gula pasir (Gulaku), pewarna sintetis makanan merah dan ungu 'food grade'. Bahan kimia meliputi: metanol (teknis) sedang $\mathrm{HCl}$, $\mathrm{Na}_{2} \mathrm{HPO}_{4}$, dan $\mathrm{KH}_{2} \mathrm{PO}_{4}$ (Merck, Jerman).

Alat-alat yang digunakan dalam penelitian ini antara lain: neraca analitik 4 desimal (Mettler, H80), juice extractor (Miyako, JE 607), shaker, lightmeter (Lutron, LX 102), spektrofotometer UV-VIS (Mini Shimadzu, 1240), gelas plastik (d $=5 \mathrm{~cm}$, tinggi $5 \mathrm{~cm}$ ), lampu 'fluorescent' (Philips Essential: 11 watt, 18 watt dan 23 watt; Sinyoku: 45 watt).

\section{Metode Penelitian}

\section{Penentuan Panjang Gelombang Maksimum Ekstrak Bit Merah (Harborne, 1987)}

Ditimbang $1 \mathrm{~g}$ umbi bit merah, dan dimaserasi secara bertingkat dengan pelarut 1 persen $\mathrm{HCl}$ dalam metanol (v/v) sebanyak $100 \mathrm{ml}$ menggunakan orbital shaker. Penentuan panjang gelombang dilakukan pada daerah 200-700 nm, dan sebagai blanko digunakan 1 persen $\mathrm{HCl}$ dalam metanol (v/v). Panjang gelombang serapan maksimum yang diperoleh digunakan untuk pengukuran absorbansi stabilitas warna agar-agar.

\section{Pembuatan Agar-agar-Bit merah}

Sari bit merah diperoleh dengan cara memasukkan potongan-potongan umbi bit merah ke dalam juice extractor, tanpa ditambah air, sehingga diperoleh cairan berwarna merah keunguan. Ditimbang 2,5 g agar-agar, ditambah dengan 31,25 g gula pasir dan $200 \mathrm{ml}$ air, dipanaskan sambil diaduk-aduk sampai mendidih. Selanjutnya, ditambah sari bit merah sesuai dengan perlakuan $(2,5 \%, 5 \%, 7,5 \%, 10 \%, 12,5 \% ; \mathrm{v} / \mathrm{v})$, dan pewarna sintetik (merah : ungu $=1: 9, \mathrm{v} / \mathrm{v}$ ) kemudian digenapkan dengan air matang sampai volumenya $250 \mathrm{ml}$. Agar- agar cair dituang ke dalam wadah pkastik transparan masing-masing sebanyak 10 $\mathrm{ml}$, dan didiamkan sampai dingin.
Uji Organoleptik Agar-agar yang diwarnai Sari Umbi bit merah (Soekarto, 1985)

Uji organoleptik dilakukan dengan 25 orang panelis dengan uji hedonik dengan 5 skala $(1=$ sangat tidak suka, $2=$ tidak suka, $3=$ agak suka, $4=$ suka, $5=$ sangat suka), terhadap warna, aroma, rasa, dan tekstur agar-agar yang diberi sari umbi bit merah dengan berbagai konsentrasi dan pewarna sintetik (campuran warna ungu dan merah).

\section{Uji Stabilitas Warna Agar-agar}

Agar-agar bit dituang ke dalam gelas plastik transparan sebanyak $10 \mathrm{ml}$ dan ditutup dengan plastik transparan. Gelas plastik berisi agar-agar sari bit disinari cahaya lampu dengan intensitas intensitas 879,06 lux, 1.688,54 lux, 2.342,2 lux dan $6.752,2$ lux dalam kotak kayu, masing-masing dengan panjang $31 \mathrm{~cm}$, lebar $40 \mathrm{~cm}$ dan tinggi 37 $\mathrm{cm}$. Sampel yang disinari diletakkan di bawah masing-masing lampu tersebut dengan jarak dari sumber cahaya lampu sekitar $20 \mathrm{~cm}$. Serta disinari cahaya matahari di ruang terbuka dari pukul 08.0013.00 .

Sampel diambil setiap 2 jam, dihancurkan hingga halus dan ditimbang sebanyak 1,0000 g. Kemudian agar-agar tersebut dimaserasi menggunakan 1 persen $\mathrm{HCl}$ dalam metanol (v/v) sebanyak $10 \mathrm{ml}$ selama 1 jam dalam erlenmeyer yang dilapisi dengan alumunium foil. Setelah itu, hasil maserasi disaring dan filtrat digenapkan dalam labu ukur $10 \mathrm{ml}$. Filtrat kemudian diukur absorbansinya pada panjang gelombang $554 \mathrm{~nm}$. Untuk agar-agar yang disinari cahaya matahari sesuai dengan yang disinari cahaya lampu, hanya pengukurannya setiap 1 jam.

\section{Pengukuran Kandungan Betalain Daging Umbi Bit Merah (Wrolstad dkk., 2001)}

0,5000 $\mathrm{g}$ daging bit dimaserasi dengan akuades sebanyak $50 \mathrm{ml}$ secara bertingkat. Filtrat yang diperoleh kemudian digenapkan dalam labu ukur $50 \mathrm{ml}$ yang telah dilapisi alumunium foil. Filtrat dilarutkan dalam larutan buffer fosfat $(0,05 \mathrm{M}, \mathrm{pH}$ 
6,5) digenapkan dalam volume tertentu agar absorbansi yang diperoleh berada pada kisaran 0,4 sampai $0,5 \pm 0,02$ pada panjang gelombang $538 \mathrm{~nm}$. Nilai absorbansinya diukur pada panjang gelombang $538 \mathrm{~nm}, 476 \mathrm{~nm}$ dan $600 \mathrm{~nm}$. Perhitungan kandungan betalain menggunakan persamaan berikut:

$$
\begin{aligned}
& x=1,095\left(A_{538}-A_{600}\right) \\
& z=A_{538}-x \\
& y=A_{476}-z-\frac{x}{3,1}
\end{aligned}
$$

Di mana, $x=$ absorbansi betanin dikurangi pengotor

$\mathrm{y}=$ absorbansi vulgaxanthin-I

$\mathrm{z}=$ absorbansi pengotor

konsentrasi betanin dan vulgaxanthin-I ditentukan dengan persamaan sebagai berikut:

$$
\begin{aligned}
& \frac{x}{1120} \times \text { Faktor pengenceran } \\
& \frac{y}{750} \times \text { Faktor pengenceran }
\end{aligned}
$$

Kandungan pigmen betalain adalah jumlah $\mathrm{C}_{\text {betanin }}$ $+\mathrm{C}_{\text {vulgaxanthin-I }}$ dengan satuan $\mathrm{g} / 100 \mathrm{~g}$.

\section{Pengukuran Pigmen Sari Bit}

Daging umbi bit merah ditimbang $25 \mathrm{~g}$, kemudian diambil sarinya menggunakan juice extractor. Volume sari bit yg diperoleh diukur (setara dengan $25 \mathrm{~g}$ ). Volume sari dari $1 \mathrm{~g}$ bit digenapkan dengan akuades sampai $100 \mathrm{ml}$. Sari bit ditambah buffer fosfat $(0,05 \mathrm{M}, \mathrm{pH} 6,5)$ digenapkan dalam volume tertentu hingga nilai absorbansi pada panjang gelombang $538 \mathrm{~nm}$ berkisar antara $0,4-0,5 \pm 0,02$. Kemudian nilai absorbansinya diukur pada panjang gelombang $538 \mathrm{~nm}, 476 \mathrm{~nm}$ dan $600 \mathrm{~nm}$. Penghitungan kandungan betalain dalam sari umbi bit merah sama dengan pengukuran betalain dalam daging umbi bit merah.

\section{Analisa Data (Steel dan Torie, 1981)}

Penelitian mengenai stabilitas warna agar-agar terdiri dari 4 perlakuan dan 6 ulangan, sebagai perlakuan adalah penyinaran lampu fluorescent dengan intensitas 879,06lux, 1.688,54 lux, 2.342,2 lux, dan 6.752,2 lux, sebagai kelompok adalah waktu analisa. Konstanta laju degradasi dianalisa menggunakan RAK (Rancangan Acak Kelompok). Untuk membandingkan konstanta laju degradasi warna agar-agar 5 persen antar perlakuan dilakukan uji BNJ dengan tingkat kebermaknaan 5 persen.

Data organoleptik dianalisa dengan RAK. Jumlah panelis sebagai ulangan. Uji organoleptik untuk menentukan konsentrasi sari daging umbi bit merah yang tepat terdiri dari 6 perlakuan, yaitu agar- agar dengan penambahan sari bit merah 2,5 persen, 5 persen, 7,5 persen, 10 persen, 12,5 persen dan pewarna sintetik. Purata skor organoleptik antar perlakuan dibandingkan dengan BNJ 5 persen.

\section{HASIL DAN PEMBAHASAN}

\section{Hasil Uji Organoleptik}

Hasil uji organoleptik dapat dilihat pada Tabel 1. yang secara umum menunjukkan bahwa semakin besar konsentrasi sari bit yang ditambahkan ke dalam agar-agar, skor yang diperoleh makin rendah, yang berarti panelis makin tidak menyukai. Untuk warna, yang paling disukai panelis adalah yang berasal dari agar-agar yang diberi sari bit 2,5 persen dan yang diberi pewarna sintetik. Untuk parameter rasa, yang paling disukai panelis adalah yang berasal dari agar-agar yang diberi sari bit 2,5 persen dan pewarna sintetik.

Untuk bau atau aroma, juga mempunyai kecenderungan yang sama, yaitu bahwa semakin tinggi penambahan konsentrasi sari bit semakin tidak disukai panelis. Hal ini karena umbi bit mengandung suatu senyawa yang disebut 'geosmin' yang menyebabkan agar-agar yang ditambah sari bit berbau seperti tanah. Konsentrasi penambahan sari bit yang paling disukai panelis 2,5 persen dan pewarna sintetik.

Untuk tekstur, penambahan sari bit yang paling disukai panelis adalah konsentrasi 2,5 pesen dan 
pewarna sintetik. Penambahan sari bit dengan berbagai konsentrasi ke dalam agar-agar menyebabkan perubahan tekstur pada agar-agar, yaitu semakin banyak konsentrasi sari bit yang ditambahkan, agar-agar menjadi semakin lunak. Jadi dalam hal ini panelis cenderung menyukai tekstur agar-agar yang lebih keras.

Penambahan sari bit pada konsentrasi 2,5 persen secara umum memberikan skor organoleptik yang tidak berbeda nyata dibandingkan dengan skor organoleptik dengan pewarna sintetik. Dengan demikian, penambahan sari bit dengan konsentrasi 2,5 persen ini berpotensi untuk menggantikan pewarna sintetik, yang masih disukai oleh panelis dan lebih aman dikonsumsi.

Selanjutnya, aga-agar dengan sari bit yang dipakai untuk uji stabilitas warna dalam penelitian ini adalah agar-agar dengan penambahan sari bit 5 persen, karena selain masih disukai panelis, juga lebih baik dari sisi kesehatan karena mengandung jumlah betalain yang lebih banyak dibandingkan dengan sari bit 2,5 persen. Agar-agar dengan penambahan sari bit 5 persen membutuhkan waktu degradasi lebih lama dibandingkan dengan penambahan sari bit 2,5 persen.

Tabel 1. Hasil Uji Organoleptik

\begin{tabular}{ccccccc}
\hline \hline & \multicolumn{5}{c}{ Perlakuan } \\
Warna & Sintetik & $2,5 \%$ & $5 \%$ & $7,5 \%$ & $10 \%$ & $12,5 \%$ \\
\hline Purata & 3,91 & 4,45 & 3,27 & 2,86 & 2,41 & 2,00 \\
\pm & \pm & \pm & \pm & \pm & \pm & \pm \\
SE & 0,2706 & 0,2260 & 0,2799 & 0,2836 & 0,2954 & 0,3060 \\
W =0,87 & $(\mathrm{cd})$ & $(\mathrm{d})$ & $(\mathrm{bc})$ & $(\mathrm{ab})$ & $(\mathrm{ab})$ & $(\mathrm{a})$ \\
\hline Rasa & Sintetik & $2,5 \%$ & $5 \%$ & $7,5 \%$ & $10 \%$ & $12,5 \%$ \\
\hline Purata & 4,17 & 4,04 & 3,13 & 2,25 & 1,96 & 1,63 \\
\pm & \pm & \pm & \pm & \pm & \pm & \pm \\
SE & 0,2385 & 0,2323 & 0,2267 & 0,2245 & 0,2915 & 0,2732 \\
W =0,89 & $(\mathrm{c})$ & $(\mathrm{c})$ & $(\mathrm{b})$ & $(\mathrm{ab})$ & $(\mathrm{a})$ & $(\mathrm{a})$ \\
\hline \hline Bau & Sintetik & $2,5 \%$ & $5 \%$ & $7,5 \%$ & $10 \%$ & $12,5 \%$ \\
\hline Purata & 4,00 & 3,75 & 3,29 & 2,63 & 2,29 & 1,88 \\
\pm & \pm & \pm & \pm & \pm & \pm & \pm \\
SE & 0,2643 & 0,2477 & 0,2419 & 0,2665 & 0,3345 & 0,3828 \\
W =1,01 & $(\mathrm{c})$ & $(\mathrm{c})$ & $(\mathrm{bc})$ & $(\mathrm{ab})$ & $(\mathrm{ab})$ & $(\mathrm{a})$ \\
\hline \hline Tekstur & Sintetik & $2,5 \%$ & $5 \%$ & $7,5 \%$ & $10 \%$ & $12,5 \%$ \\
\hline Purata & 4,08 & 3,88 & 3,52 & 3,00 & 2,64 & 2,12 \\
\pm & \pm & \pm & \pm & \pm & \pm & \pm \\
SE & 0,2643 & 0,2477 & 0,2419 & 0,2665 & 0,3345 & 0,3828 \\
W =1,08 & $(\mathrm{c})$ & $(\mathrm{c})$ & $(\mathrm{bc})$ & $(\mathrm{abc})$ & $(\mathrm{ab})$ & $(\mathrm{a})$ \\
\hline \hline
\end{tabular}

Keterangan : Angka-angka yang diikuti oleh huruf yang sama menunjukkan bahwa antar perlakuan tidak berbeda secara bermakna, sedangkan angka yang diikuti oleh huruf yang berbeda menunjukkan antar perlakuan berbeda secara bermakna. $\mathrm{W}=\mathrm{BNJ} 5 \%$.

Keterangan Skor $=(1$ : Sangat tidak suka; 2: Tidak suka; 3: Agak suka; 4: Suka; 5: Sangat suka $)$ 


\section{Spektrum Absorbsi Ekstrak Bit Merah}

Hasil scanning panjang gelombang, menunjukkan bahwa ekstrak bit merah memiliki 2 puncak absorbansi, yaitu pada $281 \mathrm{~nm}$ dan $554 \mathrm{~nm}$ dalam metanol-1 persen $\mathrm{HCl}$ (v/v) (Gambar 3).

Betalain ini memang menyerap cahaya dengan kuat pada panjang gelombang antara 532-554 nm (Harborne, 1987) yang merupakan serapan warna hijau sehingga warna yang tampak adalah ungu kemerahan (warna komplementer) (Tiley, 1999 dalam Moss, 2002).

\section{Fotodegradasi warna Agar-agar-sari bit 5\%}

Hasil penelitian menunjukkan bahwa degradasi warna agar-agar yang diberi sari bit 5 persen mengikuti pola degradasi orde-1. Hal ini sesuai dengan yang disebutkan oleh Vargas dan Lopez (2003) yang menyatakan bahwa kinetika laju degradasi betalain mengikuti pola degradasi orde-1.

Dari hasil analisa konstanta laju degradasi dapat dilihat bahwa semakin intensitas intensitas cahaya yang diberikan, konstanta laju degradasi warna merah dalam agar-agar semakin besar pula (Tabel 2 dan Gambar 4).

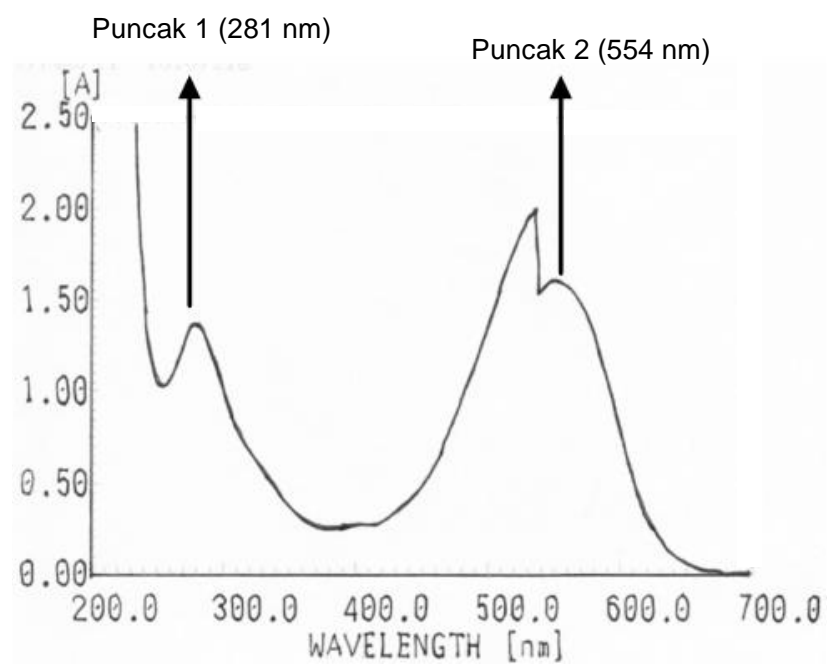

Gambar 3. Spektrum Absorbsi ekstrak umbi bit merah dalam metanol - $1 \% \mathrm{HCl}$.

Tabel 2. Konstanta Laju Degradasi Warna Agar- agar Sari Bit 5\% ( $\left.\mathrm{Jam}^{-1}\right)$

\begin{tabular}{ccc}
\hline \hline Intensitas (lux) & Purata \pm SE & \\
\hline 879,06 & $0,0468 \pm 0,0060$ & (a) \\
$1.688,54$ & $0,0565 \pm 0,0123$ & (ab) \\
$2.342,2$ & $0,0653 \pm 0,0073$ & (b) \\
$6.752,2$ & $0,0887 \pm 0,0173$ & (c) \\
\hline
\end{tabular}

Keterangan : W = 0,0204 


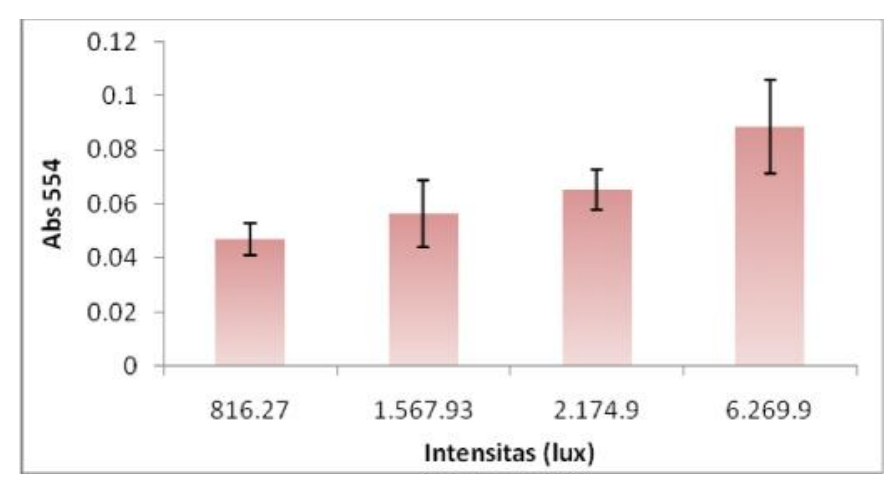

Gambar 4 Histogram konstanta laju degradasi warna agar-agar yang diberi sari bit $5 \%$ pada berbagai intensitas cahaya

Berdasarkan hal tersebut, maka intensitas cahaya yang masih dapat digunakan dalam penyimpanan agar-agar sari bit 5 persen adalah pada intensitas di bawah 1.688,54 lux karena pada intensitas lebih dari itu, warna agar-agar semakin cepat terdegradasi yang menyebabkan perubahan warna yang cukup signifikan, yaitu dari warna merah keunguan menjadi warna coklat. Hal ini sesuai dengan yang dilaporkan oleh Azeredo (2006), bahwa stabilitas betalain mulai menunjuk-kan adanya pengaruh pada intensitas antara 2200lux4400 lux. Konstanta laju degradasi warna agaragar sari bit 5 persen setelah disinari cahaya matahari (55. 263,64 lux) adalah sebesar 0,911/ jam, lebih besar dibandingkan dengan penyinaran oleh cahaya lampu flourescent. Pemaparan oleh cahaya matahari menyebabkan laju degradasi warna agar-agar semakin cepat.

Menurut Jackman dan Smith (1996 dalam Azeredo 2006) sinar UV maupun sinar tampak mampu mengeksitasi elektron $\pi$ dari gugus kromofor ke tingkat energi yang lebih tinggi $\left(\pi^{*}\right)$ karena adanya energi yang dipancarkan oleh sinar tersebut. Selain itu, Attoe dan von Elbe (1981 dalam Villota dan Hawkes 2007) mengatakan bahwa oksigen berperan penting sebagai fotokatalis dalam perusakan pigmen betalain. Berdasarkan hal tersebut diduga bahwa energi yang dipancarkan oleh cahaya merusak struktur betalain (dalam hal ini betanin) menjadi asam betalamat dan cyclo DOPA glukosida yang menyebabkan perubahan warna pada agar-agar yang diberi sari bit (Gambar 2).

\section{Kandungan Betalain Daging dan Sari Bit}

Kandungan betalain daging bit adalah 127,70 $\pm 9,34$ mg/100g berat basah (bb) (Tabel 3). Kandungan betalain ini cukup berbeda dengan kandungan betalain daging bit yang dilakukan oleh Azeredo (2006) yaitu sebesar 111,8 mg/ $100 \mathrm{~g}$ bb.

Menurut Vargas dan Lopez (2003) kandungan pigmen betalain di dalam umbi bit berkisar antara 130- $500 \mathrm{mg} / 100 \mathrm{~g} \mathrm{bb}$, tergantung dari varietas bit itu sendiri. Perbedaan kandungan ini disebabkan lokasi penanaman yang berbeda, karena seperti disebutkan dalam Wang dkk. (2006) dan Khandaker dkk. (2010) bahwa kandungan pigmen betalain dalam kultivar dipengaruhi oleh suhu dan pencahayaan pada lokasi penanaman.

Jika dibandingkan dengan kandungan betalain dari bayam merah dan cactus pear, kandungan betalain umbi bit tergolong paling tinggi. Bayam merah memiliki kandungan betalain sekitar 46$199 \mathrm{mg} / 100 \mathrm{~g}$ bb dan cactus pear memiliki kandungan betalain sebesar $15-100 \mathrm{mg} / 100 \mathrm{~g} \mathrm{bb}$ (Stintzing dan Carle, 2008).

Sari daging umbi bit memiliki kandungan betalain yang lebih rendah $(80,2 \mathrm{mg} / 100 \mathrm{~g}$ bb atau setara dengan $80,2 \mathrm{mg} / 100 \mathrm{ml}$ ) dibandingkan dengan daging umbi bit merah seperti yang terlihat pada Tabel 3 . 
Tabel 3. Kadar Betalain Umbi Bit dan Sari Umbi Bit

\begin{tabular}{lc}
\hline & $\overline{\boldsymbol{X}} \pm \mathbf{S E}(\mathrm{mg} / 100 \mathrm{~g} \mathrm{bb})$ \\
\hline Umbi Bit & $127,70 \pm 9,34$ \\
Sari Umbi Bit & $80,2 \pm 49,66$ \\
\hline
\end{tabular}

\section{KESIMPULAN}

Sari bit yang disukai panelis untuk diuji konstanta laju degradasinya setelah diaplikasikan pada agaragar adalah pada konsentrasi 5 persen.

Konstanta laju degradasi warna agar- agar yang diberi pewarna sari bit 5 persen pada intensitas: (a) 879,06 lux: 0,0468 Jam-1' (b) 1.688,54 lux: $0,0565 \mathrm{Jam}^{-1}$; (c) 2.342,2 lux: 0,0653 Jam $\mathrm{Ja}^{-1}$; (d) 6.752,2 lux: 0,0887 $\mathrm{Jam}^{-1}$. Konstanta laju degradasi warna pada agar-agar yang diberi pewarna sari bit 5 persen semakin besar dengan semakin meningkatnya intensitas cahaya.

\section{DAFTAR PUSTAKA}

Azeredo, H.M.C. 2006. Betalains: Properties, Sources, Application, and Stability-A Review. International Journal of Food Science and Technology 44: 2365-2376.

Harborne, J.B. 1987. Metode Fitokimia: Penuntun Cara Modern Menganalisis Tumbuhan. ITB, Bandung.

Jeszka. J.W. 2007. Food Colorants, dalam Sikorski, Z.E. (Ed). Chemical and Functional Properties of Food Component. p. 265-268. CRC Press LLC, New York.

Khandaker, L., A.S.M.G.M. Akond, dan S. Oba. 2009. Air Temperature and Sunlight Intensity of Different Growing Period Affects The Biomass, Leaf Color and Betacyanin Pigment Accumulations in Red Amaranth (Amaranthus tricolor L.). Journal Central European Agriculture 10(4): 439-448.
Moss, B.W. 2002. Improving Quality. dalam Macdougall, D.B. (Ed). Color in Food. p. 145-175. CRC Press LLC, New York.

Rodriguez-Saona, L.E., M.M. Giusti, dan R.E. Wrolstad. 1999. Color and Pigment Stability of Red Radish and Red-Fleshed Potato Anthocyanins in Juice Model Systems. J.Food Sci. 64 (3): 451-456.

Soekarto, S.T. 1985. Penilaian Organoleptik Untuk Industri Pangan dan Hasil Pertanian. Bhratara Karya Aksara, Jakarta.

Steel, R.G.D. dan J.H. Torie. 1981. Principles and Procedures of Statistics. Mc GrawHill Book Co. New York.

Stintzing, F.C., K.M.Herbach, M.R. Mosshammer, F. Kugler, and R. Carle. 2008. Betalain Pigments and Color Quality, dalam Chaterine A., Culver and R. E. Wrolstad (Eds). Color Quality of Fresh and Processed Food. p. 82-101. Oxford University Press, Washington DC.

Stintzing, F.C. and R. Carle, 2008. N-Heterocyclic Pigments: Betalains, dalam Carmen Socaciu (Ed). Food Colorants Chemical and Functional Properties. p. 87- 100. CRC Press LLC, New York.

Vargas, F.D. dan O.P. Lopez, 2003. Natural Colorants for Food and Neutraceutical Uses. CRC Press LLC, New York.

Villota, R. and J.G. Hawkes, 2007. Reaction Kinetics in Food Systems. dalam D.R. Heldman dan D.B.Lund (Eds). Handbook 
of Food Engineering, $2^{\text {nd }}$ Edition. p. 125-266. CRC Press LLC, New York.

Wang, C.Q., J.Q. Zhao, M. Chen, and B.S. Wang. 2006. Identification of Betacyanin and Effects of Environmental Factors on Its Accumulation in Halophyte Suaeda Salsa. Journal of Plant Physiology and Molecular Biology 32 (2): 195-201.
Wrolstad, R.E., E.A. Decker, J. Schwartz dan S. Peter. 2001. Handbook of Food Analytical Chemistry. John Wiley \& Sons Inc. Wisconsin. 